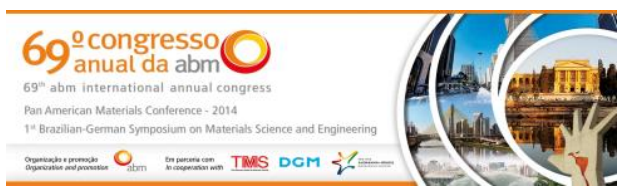

Tema: Estampagem

\title{
AVALIAÇÃO DAS CARACTERÍSTICAS MICROESTRUTURAIS DE LIGAS DE ALUMÍNIO SUBMETIDAS A TÉCNICAS DE DEFORMAÇÃO PLÁSTICA SEVERA*
}

\section{Resumo}

O presente trabalho avalia a influência de um tratamento térmico de solubilização na retenção do crescimento de grão de distintas ligas de alumínio (1200 e 8011), ao submeter estas ligas, após serem processadas por uma técnica de deformação plástica severa (Laminação assimétrica), a um tratamento térmico de recozimento para recristalização com tempos distintos de encharque. As caracterizações microestruturais e mecânicas das amostras em estudo foram avaliadas por Difração de Raios-X (DRX), análise de dilatometria e ensaios de dureza Vickers. Após o estudo realizado, concluiu-se que as ligas 1200 e 8011 na condição solubilizada apresentaram indícios de "revezamento" entre as orientações (111) e (200) no que diz respeito ao crescimento do tamanho de grãos e ao aumento da fração volumétrica dos grãos associados a essas orientações.

Palavras-chave: Ligas de alumínio; Laminação assimétrica; Deformação plástica severa; Superplasticidade.

\section{EVALUATION OF MICROSTRUCTURAL CHARACTERISTICS OF ALUMINUM ALLOY UNDER SEVERE PLASTIC DEFORMATION TECHNIQUES}

\section{Abstract}

This work evaluates the influence of solubilization heat treatment on grain growth retention of distinct aluminium alloys (1200 and 8011), after being processed by a severe plastic deformation technique (Asymmetric Rolling) and further annealing heat treatment for recrystallization with distinct soaking times. The microstructural characterizations and mechanical properties of the samples were evaluated by X-Ray Diffraction (XRD), dilatometry analysis and Vickers hardness tests. After the study, it was concluded that the 1200 and 8011 alloys in the solubilized condition showed evidences of continuous switching between the (111) and (200) orientations, probably related to grain size growth and apparent volume fraction growing of the grains associated to those orientations.

Keywords: Aluminum alloys; Asymmetric rolling; Severe plastic deformation; Superplasticity.

1 M.Sc. em Eng. Metalúrgica, Engenheiro Metalurgista, Doutorando em Ciências dos Materiais, IME, Rio de Janeiro, RJ, Brasil.

2 Doutorando em Engenharia, Faculdade de Ciências Exatas, Engenharia e Agrimensura, UNR, Província Santa Fé, Argentina.

3 D.Sc., Professora Adjunta, EEIMVR-VMT e PPGEM, UFF, Volta Redonda, RJ, Brasil.

4 D.Sc. Professor de Pós-graduação em Engenharia e Física, Faculdade de Ciências Exatas, Engenharia e Agrimensura, UNR, Província Santa Fé, Argentina.

5 Engenheira Metalurgista, Trainee, Votorantim Metais, Alumínio, SP, Brasil.

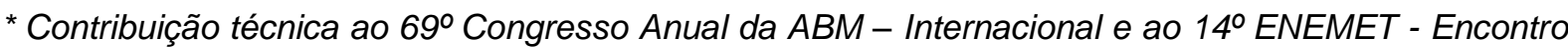
Nacional de Estudantes de Engenharia Metalúrgica, de Materiais e de Minas, 21 a 25 de julho de 2014, São Paulo, SP, Brasil.
} 


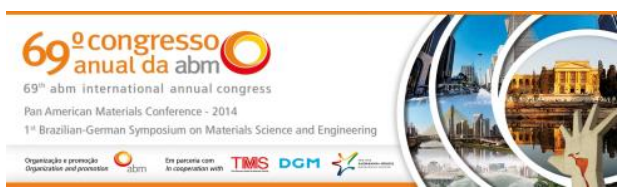

\section{INTRODUÇÃO}

De acordo com o cenário atual, vem se buscando uma maior eficiência energética, e a redução de peso em estruturas metálicas nos setores aéreo e o automobilístico, tem sido uma alternativa viável. Tal redução de peso tem sido obtida através da eliminação de processos de união como, por exemplo, a soldagem e a rebitagem. Para atingir tal objetivo, a conformação de peças com geometrias complexas é uma excelente opção e propriedade de superplasticidade, obtida através de materiais com grãos ultrafinos [1,2] tem ganhado interesse ao longo dos últimos anos e tem sido bastante estudada e posto em prática com diversas ligas de alumínio e também outros metais.

Simples métodos de conformação mecânica não são capazes de produzir materiais com o tamanho de grão na faixa em que ocorre a superplasticidade, sendo assim, técnicas chamadas de Deformação Plástica Severa (DPS) foram criadas e apresentam-se como uma alternativa viável na obtenção de materiais metálicos com grãos ultrafinos [3-5].

Para se obter a superplasticidade em materiais não é apenas necessário tamanho ultrafino de grão, mas também outras características como por exemplo, composição química do contorno de grão [1], grãos equiaxiais e recristalizados, alto ângulo de desorientação entre os grãos e a presença de precipitados ou partículas de segunda fase $[1,6]$.

Esta última característica é muito importante para a superplasticidade, pois os materiais processados por técnicas de DPS a fim de que exibam um comportamento superplástico, experimentam até duas vezes a exposição a altas temperaturas, e durante esta exposição, sem uma certa fração e dispersão destes precipitados ou partículas de segunda fase, ocorreria o crescimento do grão, e sendo assim o tamanho de grão resultante sairia da faixa em que ocorre a superplasticidade.

O presente trabalho avaliou a influência de um tratamento térmico prévio de solubilização (TT) na retenção do tamanho de grão de distintas ligas de alumínio (1200 e 8011), ao submeter estas ligas, após serem processadas por uma técnica de DPS, a um tratamento térmico de recozimento para recristalização com tempos distintos de encharque.

\section{MATERIAL E MÉTODOS}

\subsection{Material}

Os materiais utilizados para o estudo foram ligas de alumínio de nomenclatura 1200 e 8011, na forma de chapas laminadas a quente com as espessuras de 7,25 $\mathrm{mm}$ e $6,95 \mathrm{~mm}$, respectivamente, cedidas pela Votorantim Metais. A Tabela 1 mostra a composição química das chapas.

Tabela 1. Composição química das ligas 1200 e 8011 (\% em peso)

\begin{tabular}{|c|c|c|c|c|c|c|c|c|c|c|c|c|c|}
\hline \multicolumn{10}{|c|}{ Composição Química (\%) } \\
\hline Elemento & $\mathbf{S i}$ & $\mathbf{F e}$ & $\mathbf{C u}$ & $\mathbf{M n}$ & $\mathbf{M g}$ & $\mathbf{T i}$ & $\mathbf{C r}$ & $\mathbf{N i}$ & $\mathbf{Z n}$ & $\mathbf{L i}$ & Outros & Al \\
\hline \multirow{2}{*}{ Liga } & $\mathbf{1 2 0 0}$ & 0,111 & 0,430 & - & 0,010 & - & 0,030 & - & - & - & - & 0,040 & Restante \\
\cline { 2 - 12 } & $\mathbf{8 0 1 1}$ & 0,650 & 0,740 & 0,031 & 0,005 & 0,0003 & 0,021 & 0,0023 & 0,004 & 0,004 & 0,0012 & 0,0505 & Restante \\
\hline
\end{tabular}

Fonte: Votorantim Metais

\footnotetext{
* Contribuição técnica ao $69^{\circ}$ Congresso Anual da ABM - Internacional e ao 14ํㅡㄹ ENEMET - Encontro Nacional de Estudantes de Engenharia Metalúrgica, de Materiais e de Minas, 21 a 25 de julho de 2014, São Paulo, SP, Brasil.
} 


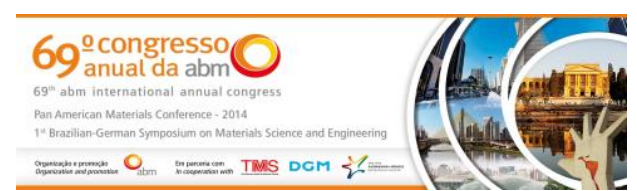

A fim de avaliar o objetivo do presente trabalho, metades dos corpos de prova foram submetidas a um tratamento térmico prévio de solubilização (TT) a uma temperatura de $500^{\circ} \mathrm{C}$ por 1 hora e resfriamento em água com agitação, onde o detalhamento método para caracterização das ligas nesta condição prévia de estudo foram reportados por Diniz et al. 2013 [7] em seu trabalho.

\subsection{Métodos}

Para a realização da Laminação Assimétrica (nomeada de LA neste trabalho), foi-se utilizado um laminador piloto no qual os cilindros de laminação giravam com a mesma velocidade $(1,676 \mathrm{rad} / \mathrm{s})$, mesmo sentido e possuíam o mesmo coeficiente de fricção, com uma razão entre os cilindros de laminação de aproximadamente de 1,18. Os corpos de prova utilizados para a LA tinham a geometria de $7 \times 14 \times 45 \mathrm{~mm}$ (direção normal $x$ direção transversal $x$ direção de laminação). A direção de laminação da chapa laminada foi a mesma da direção de LA. Tal ensaio foi conduzido a temperatura ambiente, no qual foram realizados 90 passes com uma redução da espessura de aproximadamente $4,7 \%$ por passe. A cada 10 passes de laminação, as amostras laminadas eram endireitadas e os cilindros de laminação eram 'raspados'.

Após a LA, pequenos corpos de provas com dimensões de aproximadamente $2 \times 20 \times 10$ $\mathrm{mm}$ foram cortadas através de uma máquina de corte de precisão com disco de diamante, e submetidos a um tratamento térmico de recozimento para recristalização (TTRR) a uma temperatura de encharque de $350^{\circ} \mathrm{C}$ com os tempos de encharque de $15,30,45$ e 60 minutos e posteriormente resfriados ao ar. Após o TTRR, as amostras foram embutidas a frio, e preparadas metalograficamente com lixas de carbeto de silício com granulometria de 220 a 4000 mesh e posteriormente polidas com pastas de diamante de $6 \mu \mathrm{m}, 3 \mu \mathrm{m}$ e $1 \mu \mathrm{m}$, de a modo a poder-se a analisar a seção transversal a direção transversal (DT) em relação a direção de laminação.

O ensaio de dureza Vickers (Fabricante Spectru Instrumental Científico LTDA) foi realizado com uma carga de $100 \mathrm{~g}(0,1 \mathrm{kgf})$ e com um tempo de permanência de 18 segundos. Para as amostras após a LA foram realizadas 10 medidas de dureza a 1/4, $1 / 2$ e $3 / 4$ da espessura associada à direção transversal de laminação. Tal procedimento foi realizado para verificar se há variação microestrutural / mecânica significativa ao longo da espessura das amostras estudadas.

A análise de difração de Raios- $X$ foi realizada com um difratômetro com radiação CoK $\alpha$ e goniômetro padrão. Foi aplicada uma tensão de $30 \mathrm{kV}$ e $30 \mathrm{~mA}$ de corrente durante as varreduras com acoplamento de $\theta / 2 \theta$ no intervalo de $20^{\circ}$ a $110^{\circ}$ para $2 \theta$, como intervalo de $2 \theta$ e velocidade de $2^{\circ}$ por minuto (equivalente ao tempo de aquisição de 0,6 s por ponto). As medidas relativas a intensidade relativa (\%), a área, a posição e largura a meia a altura dos picos da fase $\alpha$, a partir dos espectros de DRX foram verificadas com auxílio da função "Spectroscopy / Baseline and Peaks" disponível no "software Origin Pro 8". Esta análise foi realizada com o intuito de observar e inferir a evolução microestrutural das ligas em estudo.

Com o intuito de verificar as temperaturas associadas aos processos de restauração da estrutura deformada por meio de recuperação e recristalização da mesma, foram realizados ensaios de dilatometria em um equipamento de análise termomecânico (TMA). Os corpos de prova tiveram dimensões aproximadas de $5 \times 5 \times 2 \mathrm{~mm}$, todas as faces dos mesmos foram lixadas com lixas de abrasivos de carbeto de silício com granulometria de 320 a 4000 mesh e imersas em uma solução de $50 \%$ de ácido nítrico $\left(\mathrm{HNO}_{3}\right)$ e $50 \%$ de ácido Fluorídrico (HF) durante aproximadamente 10

\footnotetext{
* Contribuição técnica ao $69^{\circ}$ Congresso Anual da ABM - Internacional e ao 14ํㅡㄹ ENEMET - Encontro Nacional de Estudantes de Engenharia Metalúrgica, de Materiais e de Minas, 21 a 25 de julho de 2014, São Paulo, SP, Brasil.
} 


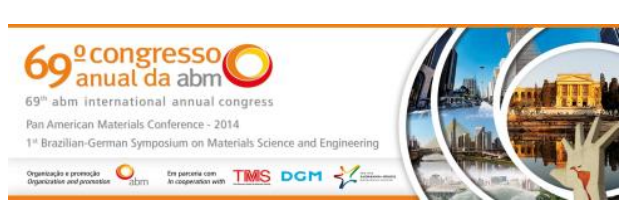

minutos. Para tal ensaio, aqueceu-se um corpo de prova deformado por LA da temperatura ambiente até a temperatura de $350^{\circ} \mathrm{C}$ (com uma taxa de aquecimento de $8^{\circ} \mathrm{C} / \mathrm{min}$ ) e com um tempo de encharque nesta temperatura de 60 minutos, e posterior resfriamento natural.

Para que a seção de Resultados e Discussão tivesse uma melhor fluidez de discussão, as amostras estudadas foram identificadas da seguinte forma:

(i) os quatro primeiro dígitos representam a liga analisada (podendo ser 1200 ou 8011);

(ii) os dois segundo dígitos indicam a condição inicial da liga ( $\mathrm{CR}=$ como recebida $\mathrm{e}$ TT = submetida ao tratamento térmico de solubilização);

(iii) os dois últimos dígitos indicam a condição final do processamento da amostra ( $L A=$ processada via $L A ; 15,30,45$ ou 60 = processada via LA e submetida ao TTRR com os tempos de encharque de 15, 30, 45 e 60 minutos, respectivamente).

\section{RESULTADOS E DISCUSSÃO}

A Figura 1 representa a média da dureza Vickers em relação o posicionamento na face analizada para as amostras (a) 1200-CR, (b) 1200-TT, (c) 8011-CR e (d) 8011TT. Na Figura 1, LA representa a amostra apenas processada por LA, e 15, 30, 45 e 60 representam o tempo de encharque utilizado para cada amostra após 0 processamento via LA.

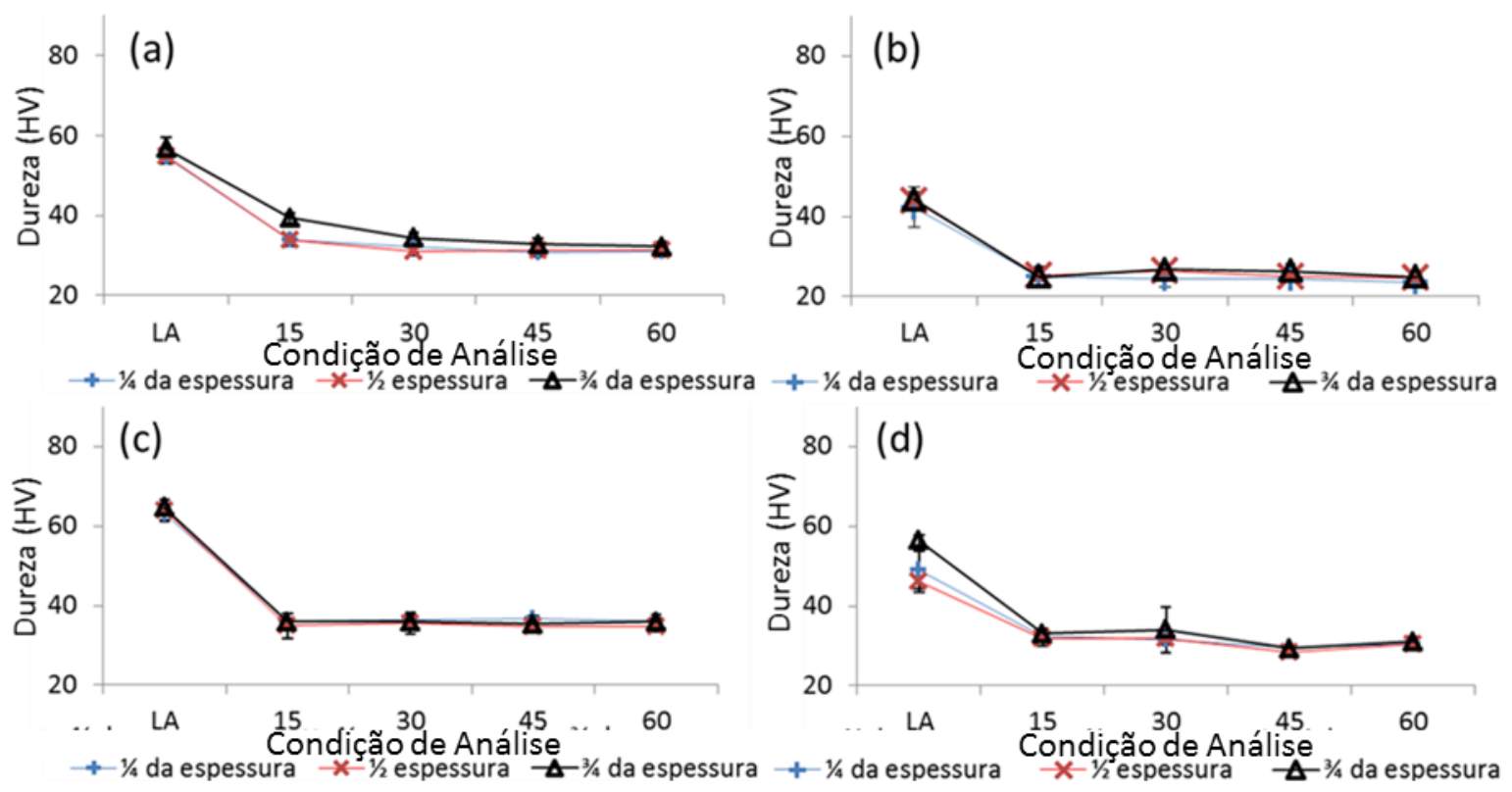

Figura 1. Evolução da dureza Vickers das amostras (a) 1200-CR, (b) 1200-TT, (c) 8011-CR e (d) 8011-TT, após o TTRR, em função do tempo de encharque, comparada a condição de LA.

De acordo com a Figura 1 para todas as amostras em estudo em suas distintas condições iniciais, há um decréscimo de dureza entre a condição de LA (laminada assimetricamente) e 15 (15 minutos de permanência no forno durante o TTRR).

Entre os tempos de encharque de 15 e 30 minutos, para a amostra 1200-CR, verifica-se outro decréscimo de dureza, tal comportamento evidencia a não completa recristalização do material. Já neste mesmo intervalo de tempo para as amostras nas condições 8011-CR, 1200-TT e 8011-TT houve uma variação insignificante do valor de dureza, que pode ser atribuido ao desvio padrão das medições de dureza.

* Contribuição técnica ao $69^{\circ}$ Congresso Anual da ABM - Internacional e ao 14ํㅡㄹ ENEMET - Encontro Nacional de Estudantes de Engenharia Metalúrgica, de Materiais e de Minas, 21 a 25 de julho de 2014, São Paulo, SP, Brasil. 


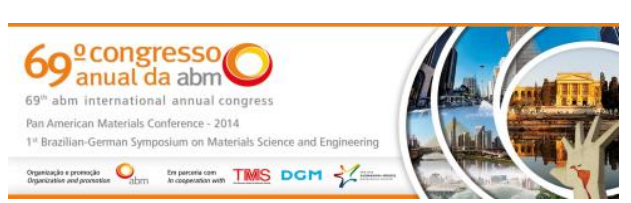

observar que as medidas para dureza obtiveram um valor constante após o tempo de 15 minutos, sendo assim os valores apresentados para a análise de dilatometria não estão em concordância com os valores de dureza. Este comportamento está provavelmente associado às capacidades das técnicas / equipamentos utilizados em auxiliar na observação do fenômeno recristalização, em função dos valores da propriedade mecânica dureza (ensaio de dureza / microdurômetro) e a outra em função da organização da estrutura interna que afeta as dimensões lineares e volumétricas da amostra em análise (ensaio de dilatometria / TMA). Onde possivelmente as modificações em função da estrutura são mais bem percebidas do que a estabilização da dureza para tempos mais próximos à real recristalização final. A Figura 3 apresenta as curvas da variação da espessura $(\Delta e)$ versus variação da temperatura no aquecimento e versus tempo de manutenção de encharque, durante os ensaios de dilatometria, para as amostras 8011-CR-LA (curva inferior) e 8011-TTLA (curva superior).
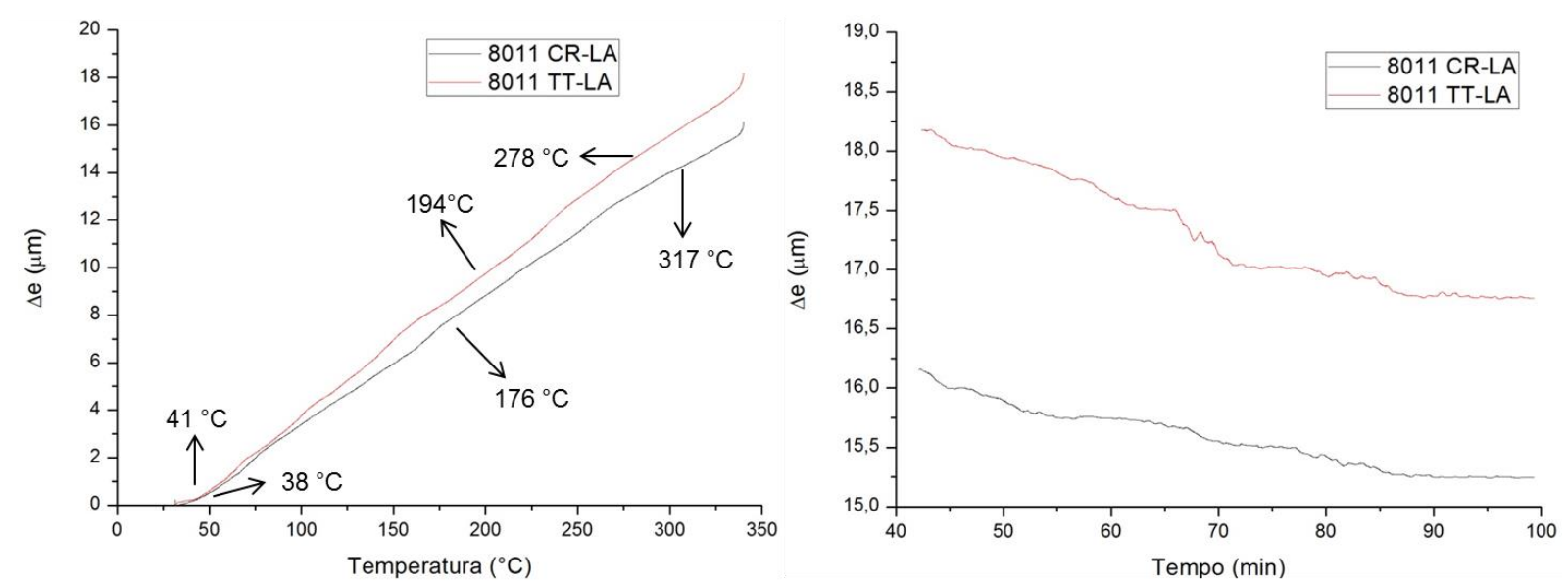

Figura 3. Curvas de Dilatometria em função da variação de $(\Delta e)$ versus Temperatura e da variação de $(\Delta \mathrm{e})$ versus tempo de encharque, para as amostras 8011-CR-LA e 8011-TT-LA.

Segundo a Figura 3 a temperatura que esta provavelmente associada ao início da recuperação para as amostras 8011 -CR-LA e 8011 -TT-LA são de $38^{\circ} \mathrm{C}$ e $41^{\circ} \mathrm{C}$, respectivamente. Os inícios das recristalizações, para as amostras 8011-CR-LA e 8011-TT-LA, ocorrem a uma temperatura aproximada de $194^{\circ} \mathrm{C}$ e $176^{\circ} \mathrm{C}$ respectivamente. Já ao final do processo de recristalização ocorre antes do patamar de $350^{\circ} \mathrm{C}$, os quais, para as amostras $8011-\mathrm{CR}$-LA e 8011 -TT-LA ocorrem a uma temperatura de $317^{\circ} \mathrm{C}$ e $278^{\circ} \mathrm{C}$, respectivamente.

Comparando as curvas $\Delta \mathrm{e}$ versus temperatura das amostras 8011-CR-LA e 8011TT-LA (Figura 3) com as curvas que descrevem a evolução da dureza Vickers com o TTRR para estas mesmas amostras (Figuras 1 (c) e (d)), pode-se observar que ambas as curvas de dureza têm um grande decaimento de dureza na condição de LA para a condição de 15 minutos, e para tempos maiores de encharque o valor da dureza não se altera. Este comportamento está de acordo com os valores obtidos pela análise de dilatometria, ou seja, antes de atingir a temperatura de $350^{\circ} \mathrm{C}$ ocorre a total recristalização da amostra 8011-CR-LA.

Dentre os quatro aspectos do perfil do pico de difração de Raios-X (posição do pico, intensidade relativa (\%), largura à meia altura e área do pico), os que mais são relevantes para caracterizar o crescimento de grão, associado a uma dada orientação, em um material, são a "Intensidade Relativa (\%)" e a "Largura à Meia

\footnotetext{
* Contribuição técnica ao $69^{\circ}$ Congresso Anual da ABM - Internacional e ao 14ํㅡㄹ ENEMET - Encontro Nacional de Estudantes de Engenharia Metalúrgica, de Materiais e de Minas, 21 a 25 de julho de 2014, São Paulo, SP, Brasil.
} 


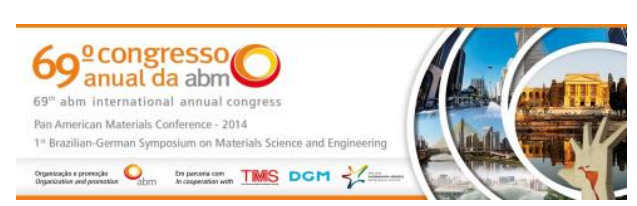

Altura (\%)". Pois se a "Intensidade Relativa (\%)" de um plano aumenta, a difração de Raios-X deste plano será maior, logo é esperado que a fração volumétrica daquela orientação aumente, e se a "Largura à Meia Altura" diminuir, indica um aumento no tamanho de grão desta orientação em detrimento do decréscimo no tamanho do grão e fração volumétrica de outras orientações.

A evolução microestrutural não será estimada durante o TTRR através da "Posição do Pico", pois esta teve uma variação pequena (em todas as condições independentes do plano analisado, tiveram uma variação inferior do que 0,6 ), e também não apresentou um comportamento nos valores que pudessem descrever um determinado comportamento, no qual tal comportamento é muito influenciado pelo posicionamento da mostra durante a análise. A evolução microestrutural também não foi estimada pela área do pico, pois está diretamente associada com as variações dos valores da "Largura a meia Altura" e "Intensidade Relativa".

As Figuras 4 e 5 apresentam os dados referentes à análise da evolução estrutural de amostras 1200-CR-LA submetidas ao TTRR com tempos distintos de encharque.

Analisando a Figura 4 pode-se verificar que não ocorreu uma mudança do pico de maior intensidade de difração (111) e menor intensidade (222) da fase $\alpha$, com exceção para o tempo de 60 minutos de encharque (1200-CR-LA), no qual o pico de menor intensidade foi o (311). Enquanto as posições intermediárias de intensidade se permutam entre os picos (200), (220) e (311) da fase $\alpha$.

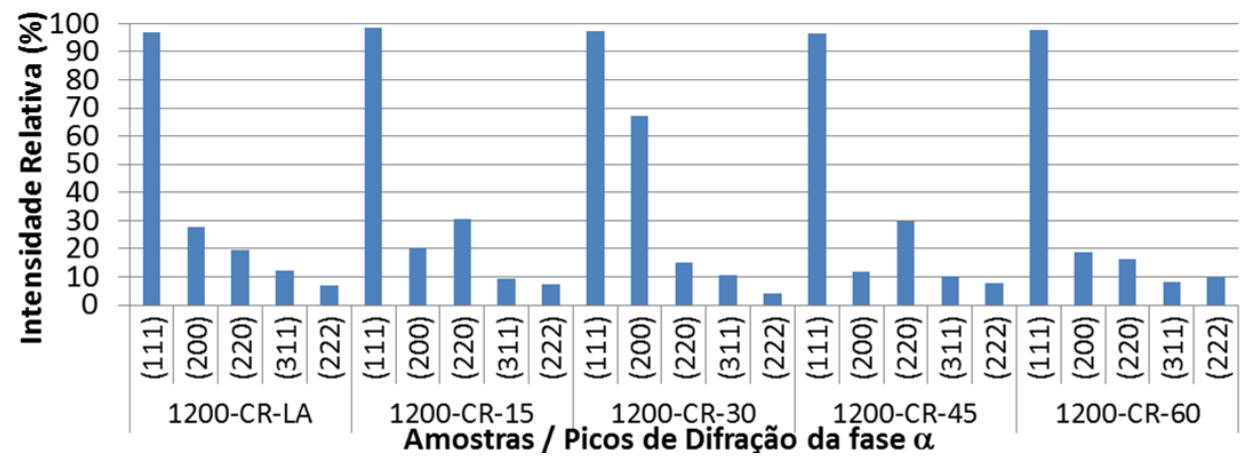

Figura 4. Efeito do TTRR nas intensidades relativas (\%) dos picos de difração de Raios-X da fase $\alpha$ para a liga 1200 na condição previa de CR.

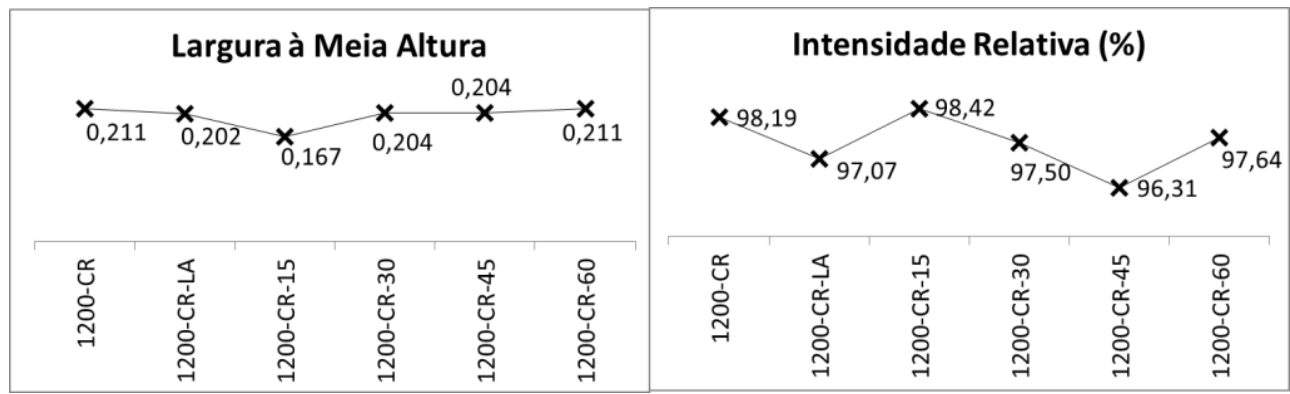

Figura 5. Efeito do TTRR no perfil do pico de difração de Raios-X (111) da fase $\alpha$, em relação à largura a meia altura e intensidade relativa (\%), para a liga 1200 a condição prévia de CR.

Com base no perfil do pico de difração de Raios-X (111) da fase $\alpha$ para a amostra 1200-CR-LA submetida ao TTRR (Figura 5), pode-se inferir de acordo com os resultados obtidos através da análise da "Intensidade Relativa (\%)" que houve um aumento da fração volumétrica dos grãos com planos (111) paralelos a DT, das condições 1200-CR-LA para a 1200-CR-15 e da condição 1200-CR-45 para a

* Contribuição técnica ao $69^{\circ}$ Congresso Anual da ABM - Internacional e ao 14ํㅡㄹ ENEMET - Encontro Nacional de Estudantes de Engenharia Metalúrgica, de Materiais e de Minas, 21 a 25 de julho de 2014, São Paulo, SP, Brasil. 


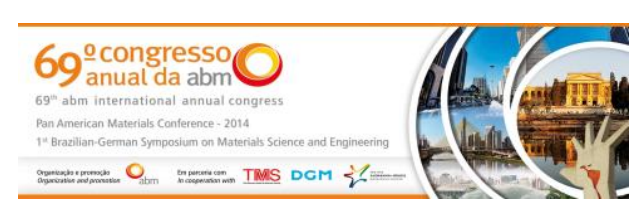

1200-TT-15, 1200-TT-30 para a condição 1200-TT-45 e 1200-TT-45 para a condição 1200-TT-60.

De acordo com a "Largura à Meia Altura" do pico (111), pode-se inferir que houve um decréscimo do tamanho de grão desta orientação, em detrimento do crescimento da fração volumétrica de outras orientações, da condição 1200-TT-LA para a 1200-TT-15 e da condição 1200-TT-45 para a 1200-TT-60. No intervalo entre 15 e 45 minutos do TTRR (condição 1200-TT-15 para a 1200-TT-45), não houve uma variação significativa na "Largura à Meia Altura", no qual esta diferença pode estar associada a pequenos desvios durante a análise de DRX, logo pode se dizer que há certa estabilidade do tamanho de grão desta orientação, enquanto que sua fração volumétrica tende a aumentar no intervalo de tempo de 15 a 30 minutos e diminuir no intervalo de 45 a 60 minutos.

Com base no perfil do pico (200) da fase $\alpha$ para a liga 1200-TT-LA submetida ao TTRR (Figura 7), pode-se observar que grãos com esta orientação no geral tiveram um comportamento oposto ao dos grãos com orientação (111). Com base na variação dos picos associados a outras orientações (220), (333) e (222), no qual não tiveram uma variação tão significativa em suas intensidades como os picos associados aos planos (111) e (200), pode-se dizer que houve certa "concorrência" entre os grãos com orientações (111) e (200), no qual quando um teve um decréscimo de fração volumétrica, houve o aumento da fração volumétrica do outro, e o mesmo comportamento se fez no tamanho de grão.

As Figuras 8 e 9 apresentam os dados referente a análise da evolução estrutural de amostras 8011-CR-LA submetidas ao TTRR com tempos distintos de encharque.

De acordo com a Figura 8, pode-se verificar que não ocorreu uma mudança do pico de maior intensidade de difração (111) e menor intensidade (222) da fase $\alpha$. Enquanto as posições intermediárias de intensidade se permutam entre os (200), (220) e (311) da fase $\alpha$.

Com base no perfil do pico (111) da fase $\alpha$ para amostra 8011-CR-LA e submetida ao TTRR (Figura 9), pode-se inferir de acordo com os resultados obtidos através da análise da "Intensidade Relativa (\%)" que houve um aumento da fração volumétrica dos grãos orientados a (111), das condições 8011-CR-15 para a 8011-CR-30 e da condição 8011-CR-45 para a 8011-CR-60, e um decréscimo da fração volumétrica da condição 8011-CR-LA para a 8011-CR-15 e da condição 8011-CR-30 para a 8011-CR-45.

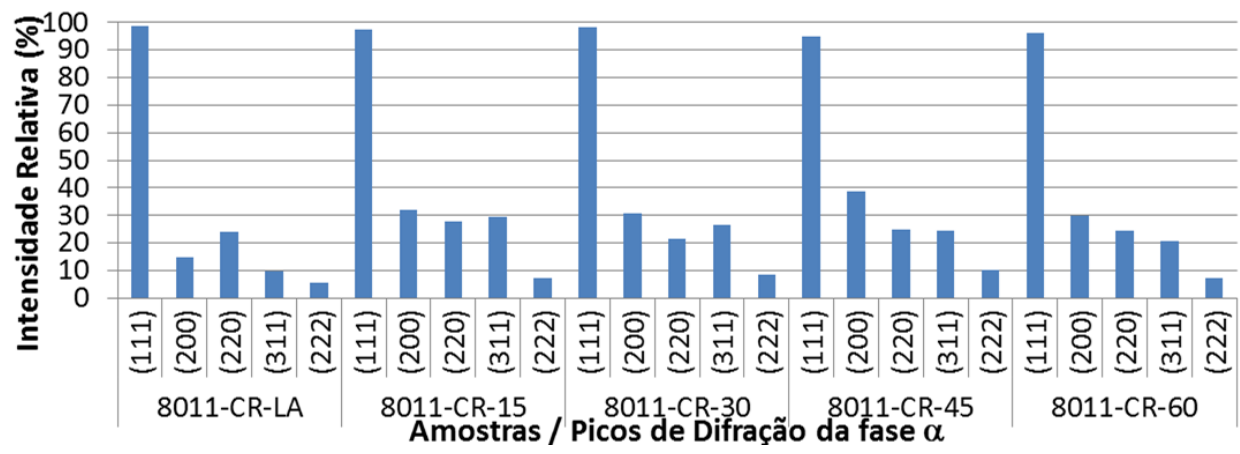

Figura 8. Efeito do TTRR nas intensidades relativas (\%) dos picos de difração de Raios-X da fase $\alpha$ para a liga 8011 na condição prévia de CR.

De acordo com a "Largura à Meia Altura", pode-se inferir que houve um crescimento do tamanho de grão associado a grãos de orientação (111), em detrimento do decréscimo e fração volumétrica de outras orientações, da condição 8011-CR-LA

\footnotetext{
* Contribuição técnica ao 69 Congresso Anual da ABM - Internacional e ao 14ํㅡㄹ ENEMET - Encontro Nacional de Estudantes de Engenharia Metalúrgica, de Materiais e de Minas, 21 a 25 de julho de 2014, São Paulo, SP, Brasil.
} 


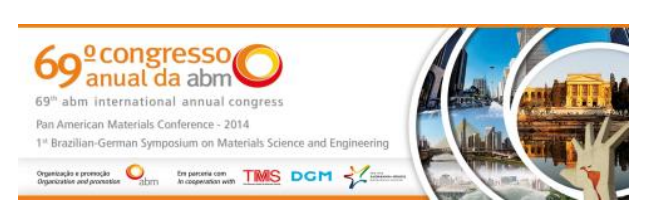

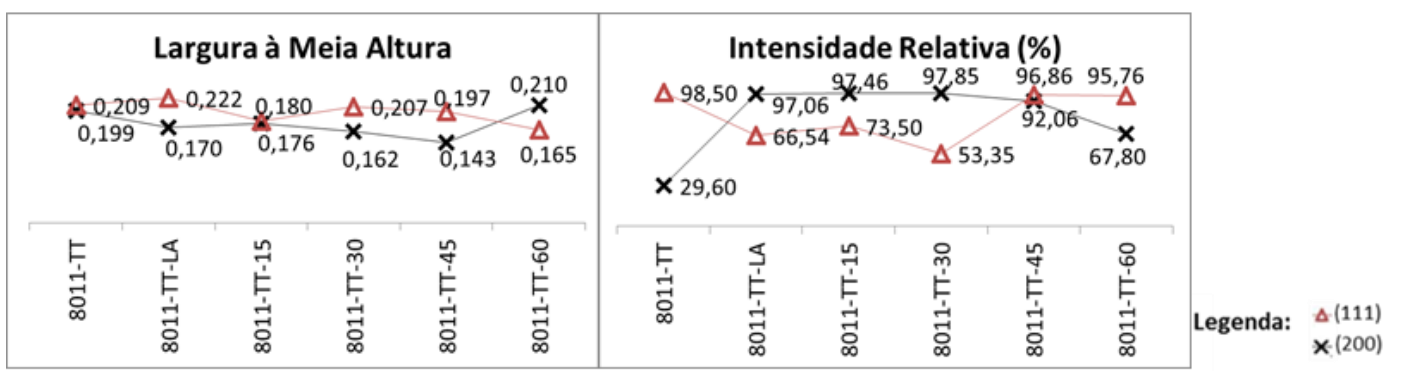

Figura 11. Efeito do TTRR no perfil dos picos de difração de Raios-X (111) e (200) da fase $\alpha$, em relação à largura a meia altura e intensidade relativa (\%), para a liga 8011 na condição prévia de TT.

De acordo com a "Largura à Meia Altura" do pico (111), pode-se inferir que houve um decréscimo do tamanho de grão, em detrimento do crescimento da fração volumétrica de outras orientações, da condição 8011-TT-45 para a 8011-TT-60, um crescimento de grão da condição $8011-T T-15$ para a 8011-TT-45 e da condição 8011-TT-LA para a 8011-TT-15, não houve uma variação significativa na "Largura à Meia Altura", no qual esta diferença pode estar associada a pequenos desvios durante a análise de $\mathrm{DRX}$, logo pode se dizer que há certa estabilidade do tamanho de grão desta orientação, enquanto que sua fração volumétrica aumentar neste mesmo intervalo.

Da mesma forma que ocorreu com a liga 1200, os grãos de orientação (111), no geral, tiveram um comportamento oposto ao dos grãos com orientação (200) para a liga 8011 na condição prévia de TT, sendo assim pode-se dizer que houve certa "concorrência" entre os grãos com orientações (111) e (200), no qual quando um teve um decréscimo de fração volumétrica, houve o aumento da fração volumétrica do outro, e o mesmo comportamento se fez no tamanho de grão.

Com base nos resultados do perfil dos picos de difração de Raios-X, fazendo-se uma comparação da condição CR para a TT, pode-se supor que possivelmente o tratamento térmico de solubilização pode ter ocasionado certa estabilidade no crescimento dos grãos, pois quando se observa apenas na condição prévia de CR, observaram-se apenas picos de maiores intensidades associados ao plano (111) para todas as duas ligas em estudo, e este fato se manteve durante todo o TTRR (Figuras 4 a 11). Já para a condição de TT para as ligas 1200 e 8011, a maior intensidade já se fez presente para os planos associados a (111) e (200) (Figuras 7, 8, 11 e 12), sendo assim de acordo com a análise do perfil dos picos associados a estes planos, é possível que para as ligas 1200 e 8011 possa ter acontecido o "revezamento" do crescimento / decréscimo do tamanho dos grãos e aumento / diminuição da fração volumétrica para os grãos de orientação (111) e (200), uma vez que a variação da intensidade associada aos planos (220), (331) e (222) (Figuras 4, 6,8 e 10), não foi tão significativa quanto às dos planos (111) e (220).

\section{CONCLUSÃO}

Com base nos resultados apresentados e discutidos, conclui-se que:

I - De acordo com os resultados da análise de dilatometria e de dureza Vickers:

(a) Para a liga 1200 (nas condições de CR e TT) houve a total recristalização das amostras no decorrer do tempo de encharque estabelecido;

(b) Para a liga 8011 (nas condições CR e TT), houve a completa recristalização antes das amostras atingirem o patamar de $350^{\circ} \mathrm{C}$.

\footnotetext{
* Contribuição técnica ao $69^{\circ}$ Congresso Anual da ABM - Internacional e ao 14ํㅡㄹ ENEMET - Encontro Nacional de Estudantes de Engenharia Metalúrgica, de Materiais e de Minas, 21 a 25 de julho de 2014, São Paulo, SP, Brasil.
} 
